\title{
El Retorno del Regionalismo. Aspectos Políticos y Económicos en Los Procesos de Integración Internacional
}

\author{
Raúl Bernal-Meza \\ Gustavo Alberto Masera*
}

Resumen: Las políticas que han orientado la formación de regiones en la economía mundial en las últimas décadas, tienen su origen en el orden internacional que emerge de la conferencia de Bretton Woods. En los países centrales (Europa) y América Latina, aunque por diferentes razones, se impulsaron políticas específicas de cooperación regionales. Una renovada intensificación de los procesos de integración tiene lugar desde mediados de la década de los 80 s. Los nuevos regionalismos implican cambios cuantitativos y cualitativos con respecto a etapas anteriores, aunque no suponen nuevas estrategias de desarrollo. Argumentamos que en la fase contemporánea de las relaciones internacionales, los espacios integrados no pueden aislarse del estudio del orden mundial ni del fenómeno de la globalización.

Palabras-clave: Integración Regional, Relaciones Internacionales, Regionalismo, Globalización.

Abstract: The policies that have driven the formation of regions, in the world economy during the last decades, have their origin in the international order that had emerged from the Bretton Woods conference. The central (Europe) and Latin American countries, although for different reasons, have promoted policies of regional cooperation. A renewed intensification of the integration processes has taken place from the mid 80s of the XX century. The new regionalisms imply both qualitative and quantitative changes with respect to the previous periods, though they not entail new development strategies. We defend that, in the current phase of the international systems, the already integrated spaces should neither isolate themselves from the consideration of the world order, nor ignore the globalization phenomena.

Keywords: Regional Integration, International Relations, Regionalism, Globalization.

* Raúl Bernal-Meza: Universidad Nacional del Centro de la Provincia de Buenos Aires. E-mail: bernalmeza@ hotmail.com. Gustavo Alberto Masera: Programa de Relaciones Internacionales y MERCOSUR de CRICYTCERIAL. E-mail: gam@lab.rricyt.edu.ar. Recebido em 02/06/08 e aceito em 12/06/08. 


\section{Introducción}

En este documento analizamos la formación de acuerdos regionales de comercio, surgidos en el contexto del orden económico de la segunda mitad del siglo XX, con proyección a los inicios del siglo XXI. Partimos del supuesto de que sólo es posible comprender los cambios que han tenido lugar en el sistema internacional -su forma actual, sus contradicciones, sus tendencias y conflictos- si se los analiza desde un punto de vista histórico (KRIPPENDORFF, 1985; BERNAL-MEZA, 2000). Este enfoque se sustenta en el principio de que el conocimiento del pasado puede ofrecernos indicios, también regularidades, sobre posibilidades futuras. En particular, nos facilita la realización de estudios prospectivos sobre la evolución de los escenarios regionales e internacionales.

\section{Integración regional en la economía mundial}

El sistema internacional contemporáneo ha sufrido enormes transformaciones en las últimas décadas. Entre ellas, podemos identificar cuatro principales: a) la caída del bloque comunista de economías de planificación centralizada y el desmembramiento de la Unión Soviética, junto a la transición de estos países hacia una economía de mercado; b) la unificación de la economía mundial mediante un proceso multidimensional y complejo de globalización/mundialización, en un escenario internacional de fuertes asimetrías ${ }^{1}$ en donde conviven fuerzas centrífugas de dispersión, fragmentación y crisis, con centrípetas de entrelazamiento e interdependencia; c) la vigencia de un paradigma socio-tecnológico que incluye nuevos modelos de producción científico-tecnológicos, localizados en sistemas de innovación territoriales de alta especialización para la generación de tecnologías digitales, infraestructuras y redes de acceso universal, todo lo cual está generando un nuevo tipo de organización que denominamos sociedad de la información d) una renovada tendencia a la formación de espacios regionales de comercio e inversiones, con agendas de discusión inéditas por la variedad de temas y el

\footnotetext{
${ }^{1}$ Las principales asimetrías se refieren a la altísima concentración del progreso técnico en los países desarrollados y, en particular, a la ampliación de la brecha digital; la mayor vulnerabilidad macroeconómica de los países en desarrollo ante los shocks externos; y la asociada al contraste entre la movilidad de los capitales y la restricción al desplazamiento internacional de la mano de obra (CEPAL, 2002; BERNAL-MEZA, MASERA, 2007).
} 
alcance de las negociaciones, en una dinámica de regionalización del sistema internacional.

Nuestro punto de partida es que en esta etapa de la coyuntura mundial, no se pueden separar los macroprocesos anteriormente enumerados, en particular el de los cambios en la política internacional -del paradigma EsteOeste al escenario de la postguerra fría- y el de la evolución de la economía -desde la conferencia fundacional de Bretton Woods en 1944 que impulsó la institucionalización del orden económico internacional y legitimó la hegemonía norteamericana- hacia un capitalismo global.

El hecho que los aspectos tradicionalmente denominados como de "baja política", como son aquellos vinculados a la economía, el comercio, las finanzas y la tecnología -e incluso otros, como los que se relacionan con los derechos sociales y la gobernanza (porque ahora se mira más al interior de los Estados) hayan desplazado en buena medida las prioridades que antes se asignaban a la seguridad y los aspectos diplomático-políticos y militar-estratégicos, considerados como de "alta política", ha implicado el surgimiento de nuevas prioridades, una de las cuales es la primacía de las negociaciones económicas internacionales y, por tanto, el desarrollo de la diplomacia económica (BAYNE, WOOLCOOK, 2003).

Argumentamos que el destino que adoptan las corrientes financieras, las estrategias de localización de las grandes firmas internacionales, el desarrollo desigual que comportan las lógicas asociadas a la creación de economías de aglomeración -gracias a la acumulación de factores que posibilitan que una región se transforme en un polo de crecimiento con industrias motrices- (KRUGMAN, OBSTFELD, 1999), y la direccionalidad de los movimientos en las transacciones de comercio, dan lugar a importantes cambios estructurales en las relaciones internacionales.

En particular, constatamos que la economía mundial se está polarizando en un regionalismo continental con tres núcleos regionales principales. En estas áreas económicas se ven reforzados los vínculos más estrechos entre Estados que comparten un ámbito geográfico, histórico, cultural y económico, y que estarían centrados en torno de las economías más dinámicas (dados los niveles de flujos de inversión y corrientes de comercio recíprocos) y sus respectivos mercados. Los polos de integración de la tríada mundial, serían 
Norteamérica, con el liderazgo de los Estados Unidos, Europa occidental y central, con la centralidad de la Unión Europea, y la zona económica AsiaPacífico, con el predominio de Japón y China (BERNAL-MEZA, 1994b; 2000; BERNAL-MEZA, MASERA, 2005).

Al observar estos cambios debemos realizar una primera diferenciación analítica. Si la regionalización es el proceso mediante el cual se conforman áreas regionales de comercio en la economía mundial, el regionalismo es tanto el sistema de ideas que actúa como teoría de la diversificación de los espacios de integración en el escenario internacional, como el criterio normativo que permite la formulación de políticas orientadas a la construcción de esquemas institucionales regionales.

En la economía mundial, la evidencia muestra que la regionalización promueve fuerzas que tienden a integrar en un mismo espacio regional a países geográficamente próximos y económicamente complementarios, por lo menos en lo que respecta a la acumulación de recursos y en el aumento de las dimensiones del mercado. Pero, si las fuerzas de la integración regional son consideradas centrípetas o centrífugas, depende del enfoque teórico utilizado y de la carga valorativa previa que adopta el analista. Porque, aunque el instrumental nos demuestre que existe una mayor creación de comercio en un área regional determinada, el esfuerzo de regionalización puede estar sesgado hacia el aumento de la polarización global y el desarrollo desigual de las regiones en el mundo o hacia procesos de "armonización imperial”. Por esta razón consideramos que una correcta comprensión del significado de los espacios de integración, obliga, previamente, a vincular éstos con la reflexión sobre el orden mundial.

\section{Regionalismo y orden mundial}

El orden mundial es un conjunto de normas e instituciones que reflejan una determinada hegemonía de una estructura histórica particular. Además, representa un cierto consenso sobre la aceptación de determinadas prácticas y reglas, fuera de las cuales los Estados no podrían existir.

Debemos tener en cuenta que el hecho de que existan al interior del sistema-mundo distintas unidades políticas -los Estados-nación, que son el aspecto político de la forma de acumulación dominante llamada capitalismo- 
se explica por la naturaleza misma del sistema mundial: una organización también estatal, pero cuyo vínculo clave es económico y no político. Sin embargo, el proceso de mundialización actual tiene componentes esencialmente distintos (en términos de actores), pero no por ello diferentes en la lógica que fundamenta su gestión: la acumulación permanente; así como los recursos a la ideología, como instrumentos para impulsar el mismo (WALLERSTEIN, 1985).

Otra manera de pensar el asunto parte de la perspectiva que considera a los órdenes mundiales como estructuras históricas, en las que interactúan tres categorías de fuerzas: atributos materiales de poder, ideas (intereses e ideologías) e instituciones (COX, 1986). Simplificadamente, si aplicamos la perspectiva de Cox a las condiciones del sistema internacional contemporáneo podemos decir que: a) los atributos de poder, en tanto capacidades para determinar el curso de los procesos políticos y económicos mundiales, estarían representados, por ejemplo, por la relación estratégica Estados Unidos de América con la Organización para el Tratado del Atlántico Norte (OTAN); b) las ideas, en cuanto esquemas conceptuales, modelos e ideologías, por ejemplo, la sociedad de la información (esto es, el nuevo paradigma sociotecnológico y la nueva forma de organización social caracterizada por el predominio de los sectores info-comunicacionales) ${ }^{2}$; c) las instituciones, representadas por 1.) Los organismos, organizaciones, agencias especializadas o regímenes (en lo que se refiere a organismos internacionales de carácter intergubernamental o multilateral, el G-8, Banco Mundial, Fondo Monetario Internacional, o la Organización Mundial de Comercio); o 2.) Los acuerdos regionales de comercio y bloques regionales internacionales con estilos de integración institucionalizados en mayor o menor grado.

En última instancia, el regionalismo está inevitablemente vinculado al ámbito multilateral y al orden mundial, porque todo proceso particular de regionalización genera repercusiones sistémicas por los alineamientos estratégicos que producen los países que construyen la región y que modifican la situación relativa de éstos en la economía mundial y, porque conllevan estrategias de alianzas que inciden y/o determinan el curso de negociaciones

${ }^{2}$ Los principios rectores que dirigen la construcción de la sociedad de la información son auspiciados, por ejemplo, por las Naciones Unidas, junto a la labor de agencias especializadas y organizaciones internacionales como la Unión Internacional de Telecomunicaciones, la UNESCO, y la Alianza Global para el Desarrollo de la Información. 
multilaterales como, por ejemplo, lo han sido -en la historia contemporánealos debates sobre la cooperación y el desarrollo; las negociaciones por el nuevo orden económico mundial y la reformulación del GATT con su posterior transformación en la Organización Mundial de Comercio (OMC).

\section{Construcción regional e integración}

Los países se plantean la posibilidad de participar en un proceso de integración regional porque prevén que con esta agrupación pueden obtener mayores beneficios políticos y económicos que si continúan aislados. En este sentido, la percepción de que en un mundo globalizado, las economías pueden ser más competitivas, con mayor poder de negociación y de inserción internacional si cooperan con otras, se relaciona con el aumento de la conciencia regional (HURRELL, 1994)

La construcción de una región descansa en elementos comunes básicos, que facilitan la tarea de la integración: a) la proximidad: a pesar de que las regiones son, a priori, comunidades más imaginadas que reales (SMOUTS, 1997), es evidente que las mismas tienden a conformarse en aquellos ámbitos territoriales en donde existen factores comunes previos, ya sean éstos históricos, culturales, o geográficos. Es por ello que no sería erróneo hablar de regiones naturales con una identidad propia, y con un peso tal como para ser reconocidas como actores unitarios en el escenario internacional; b) valores fundamentales compartidos: como por ejemplo, la promoción de un sistema político, la búsqueda del desarrollo socioeconómico regional; la industrialización; el crecimiento económico redistributivo y, en términos del más reciente paradigma de la Comisión Económica para América Latina y Caribe de Naciones Unidas (CEPAL), la transformación productiva regional con equidad; c) estrategias de gobernanza común: amplios y complejos vínculos de participación, tanto de actores públicos como privados, en términos de acciones socio-políticas conjuntas, integrando programas y decisiones de gobierno junto a una adecuada participación de las comunidades (sociales, étnicas, políticas) y de los agentes socioeconómicos en una orientación abajo-arriba (bottom-up) y no sólo arriba-abajo (top down). Estas prácticas le confieren legitimidad y credibilidad al proceso de integración y cooperación regional, puesto que permiten evitar conflictos de 
intereses, al pensar no sólo en lo inmediato (en la medida que decisiones de tal tipo conllevan predisposiciones a optar por uno u otro camino; cada uno de ellos vinculado a sectores que en lo inmediato reciben beneficios, versus otros que son postergados en el tiempo), sino en el interés del conjunto a largo plazo, en el marco de una estrategia coherente y adecuada entre los múltiples factores políticos, económicos y culturales involucrados.

En su proceso de acercamiento entre sí estos países pueden implementar mecanismos para cooperar y compartir responsabilidades con la finalidad última de lograr objetivos comunes en áreas específicas, como puede ser por ejemplo, en el ámbito de un programa de protección del medio ambiente o en el desarrollo de programas científicos (BAALAM, VESETH, 2004). Pero, desde una óptica estrictamente económica, la integración regional supone el proceso de acercamiento y coordinación de las economías de dos o más países de modo de constituir un territorio económico común. Sus objetivos principales pueden ser entre otros, la creación de comercio; la generación de un mayor nivel de competencia intrabloque; el aprovechamiento de economías de escala; la cooperación intrarregional en proyectos de innovación tecno-industriales asociados incluso mediante el progreso hacia nuevas actividades; una más eficiente y mejor racionalización de la producción mediante una división regional de la industria; la generación de mecanismos de financiamiento regional; la complementación económica; y, por ultimo, la sinergia en los frentes de negociación internacional (BALASSA, 1980). Tengamos en cuenta que, a pesar de los beneficios evidentes, la integración puede generar también costos sectoriales y efectos negativos puertas adentro y hacia fuera del acuerdo.

\section{Cooperación e integración económica regional}

Una distinción entre los términos de cooperación e integración se hace aquí necesaria. A pesar de que no existe una frontera claramente delimitada entre ambos conceptos, su utilización equívoca puede derivar en confusión. Mientras que la cooperación es posible entre países que tienen distintos sistemas monetarios, fiscales, de seguridad social y hasta con una visión completamente distinta de la organización de la empresa y los mercados, la integración plena es factible cuando se ha llegado a una armonización muy 
profunda del marco institucional de la economía ${ }^{3}$.

La integración supone una acción de política económica más específica y profunda que la cooperación. La integración contempla una primera tarea, orientada a la reducción de barreras y obstáculos, para dar a las transacciones económicas una mayor flexibilidad; en una segunda etapa se persigue la supresión absoluta de tales barreras, a fin de crear un mercado único, sin trabas fronterizas, y con la mayor transparencia en las tarifas no arancelarias. El concepto clave es la armonización de políticas, en la medida en que ésta supone la supresión de políticas de tratamiento diferencial entre los países miembros del acuerdo.

Lo anterior se traduce, desde una perspectiva de linealidad económica, en el acercamiento progresivo de los países firmantes de un acuerdo, con el fin de eliminar restricciones comerciales, discriminaciones o diferenciaciones (normas técnicas, medios de pago, etc.) y las trabas a la movilidad de los factores productivos. Además, en un acuerdo de integración se incorporan, de manera gradual, compromisos que se reflejan en un particular nivel de integración (zona de libre comercio, unión aduanera, mercado común) para llegar, por fin, al establecimiento de una unión monetaria y económica. Mediante el proceso de acercamiento y de articulación de los mercados y las sociedades, los países tienden a coordinar sus políticas, en un amplio abanico que va desde las políticas microeconómicas e industriales hasta las políticas macroeconómicas, como por ejemplo sucede con las monetarias, que permiten las construcción de áreas monetarias óptimas (TUGORES, 2004).

En última instancia, la integración económica se refiere al proceso en virtud del cual países y mercados previamente separados, se incorporan al funcionamiento de una nueva unidad considerada de dimensiones geoeconómicas más adecuadas (TAMAMES, HUERTA, 1999). La integración puede darse en niveles muy diferentes, que van desde una coordinación mínima y ajuste recíproco de la conducta de las partes involucradas hasta la renuncia a aspectos de soberanía política de éstas, en la medida en que los actores pasan a constituir una nueva entidad. Este acercamiento se ve

\footnotetext{
${ }^{3}$ Para la distinción entre los conceptos de cooperación e integración véase James Caporaso (1987), Raúl Bernal-Meza (2001) y Alcides Costa Vaz (2002).
} 
facilitado cuando se realiza entre países geográficamente próximos, con capacidad de interacción regular de una cierta intensidad entre sí. Además, éstos deben tener la capacidad de verse y de ser vistos como un actor con identidad propia en el escenario regional e internacional. Es decir, comparten un sentido de identidad regional y son reconocidos como tal por actores externos (ATKINS, 1991).

La regionalización es, entonces, tanto el proceso de creación específica de un espacio común, como el resultado de la puesta en marcha de la integración. El proceso supone, entre otros objetivos: poner en contacto economías relativamente homogéneas y de nivel de desarrollo relativo comparable en la trayectoria de acoplamiento progresivo de las estructuras socio-económicas; la convergencia política, a fin de crear instituciones comunes que permitan seguir, cuando sea necesario, una política coordinada en los ámbitos monetarios, financieros, industriales, comerciales, etc. Aunque el énfasis se encuentra en los aspectos económicos, por las razones previas se debe reconocer que un proceso de regionalización no es puramente económico, sino simultánea y sistémicamente, político, social y cultural (BERNALMEZA, 2000).

\section{Globalización/mundialización}

En los inicios del siglo XXI se ha perfilado una nueva situación en la economía mundial que afecta a los procesos de regionalización. En otros trabajos hemos definido nuestra posición acerca de los orígenes de la globalización, y la actual etapa de mundialización como el eslabón más actual de la acumulación capitalista. Esta visión se sustenta, asimismo, en el pensamiento de diversos autores con los cuales compartimos una similar concepción histórico-estructural de interpretación del sistema mundial (WALLERSTEIN, 1985; KRIPPENDORFF, 1985, BERNAL-MEZA, 2000).

Diferenciamos analíticamente la mundialización como proceso prioritariamente económico y tecnológico, de su carácter como ideología, que es la globalización en sentido estricto. En líneas generales, argumentamos que el proceso de globalización/mundialización es un fenómeno amplio y complejo, no consolidado, que identifica y expresa la intensificación 
de flujos portadores en espacio y tiempo, de nuevas formas de pensar, de producción, de vinculación y de relación; proceso que sin ser nuevo en la historia, se ha profundizado y acelerado, durante los ańos recientes, en especial en los aspectos financieros. Pero, junto a ello, la globalización ha pasado a ser un paradigma; un modelo ideológico, bajo el cual se escudan o justifican políticas internacionales y nacionales; cuyas consecuencias negativas se están progresivamente internalizando en los países; en particular, en los subdesarrollados, periféricos o semiperiféricos. La globalización es un fenómeno de convergencia de diversas variables y factores de las principales economías del mundo en el que coexisten tendencias de homogenización y fragmentación. Desde un punto de vista de las ideologías dominantes, representa la nueva visión del mundo del capital que justifica la financiarización de la economía internacional. Es un paradigma que -como tal- expresa un marco conceptual, eidético, interpretativo y prescriptivo, cuyo origen está en las sociedades, grupos y poderes dominantes y se difunde hacia las sociedades que integran el sistema mundial; desde el centro hacia la periferia (BERNALMEZA, 2000).

La globalización no es un fenómeno distinto, diferente, autónomo de la historia social y económica del sistema internacional, sino que es eslabón de un largo proceso, tal como han sugerido Tomassini (1984) y Sunkel (1987); iniciado con la internacionalización y seguido luego por la transnacionalización de las economías nacionales.

La existencia de la globalización es posible sólo y dentro de un sistema mundial, cuya característica estructural es la expansión del modo de acumulación dominante, mediante determinados impulsores que la motorizan. Entre ellos, mencionamos la ampliación de los ámbitos de acción de las firmas internacionales, asociado al crecimiento del volumen y tipo de los negocios internacionales; la mundialización de las finanzas; la aparición de nuevas formas de organización empresaria vinculadas con modernos paradigmas de gestión (por ejemplo, redes tecnoeconómicas, redes de investigación más desarrollo e innovación $\mathrm{I}+\mathrm{D}+\mathrm{i}$, alianzas de firmas, clusters); la aplicación de diversas estrategias empresariales (deslocalización y relocalización geográfica industrial; encadenamientos globales; terciarización en el sentido de subcontratación y de prioridad del sector terciario de la 
economía; segmentación/partición de la cadena de valor) en un marco de hipercompetencia por el liderazgo, el posicionamiento competitivo y la participación en los mercados internacionales; la aparición de un sistema genérico de economía de mercado, en donde participan diversas estructuras político-institucionales que responden a formas distintas de interpretar la relación entre Estado, mercado y sociedad, y por último, la aparición de renovadas formas de competencia regional mediante la proliferación de bloques regionales y acuerdos de cooperación e integración.

\section{Análisis de la globalización y la regionalización}

La regionalización, en su relación con la dinámica de globalización/ mundialización, puede ser analizada bajo dos perspectivas: a) la que considera que los mismos son dos procesos simultáneos en comercio, inversión y desarrollo tecnológico, aunque distinguibles por su naturaleza: mientras que la regionalización es un proyecto político-económico esencialmente Interestatal, la globalización es un proceso socialmente complejo y multidimensional. Aquí se interpreta que el rumbo de la economía mundial tiende a dos procesos no exactamente coincidentes, aunque por momentos puedan tener trayectorias paralelas (como motores de la integración global), o quizás contrarias (globalización versus regionalización); b) la que los examina como procesos derivados causalmente, esto es, que uno genera o es principio del otro. Esta última diferenciación tiene a su vez dos posibilidades de lectura, 1) donde la formación de regiones sería un corolario o consecuencia de la creciente globalización. A favor de este punto se plantea que hasta ahora la globalización no ha generado un mundo en el cual las naciones interactúen con otras igualitariamente, sino que, más bien, la actividad económica, aunque parezca más dispersa, se está concentrando crecientemente en las tres grandes regiones continentales (América del Norte, Europa y Asia-Pacífico); 2) donde el surgimiento de regiones internacionales constituiría una realidad anterior a la globalización. La articulación progresiva de espacios y bloques conformaría una trama compleja de ámbitos de cooperación e integración, que permitiría impulsar el desarrollo de un entorno global.

Si los movimientos hacia la globalización y la regionalización son simultáneos, es casi inevitable el surgimiento de tensiones, ya que las 
agrupaciones regionales limitan de hecho la globalización absoluta de la economía mundial. Este conflicto estaría afectando la continuidad y la implantación de un sistema internacional de comercio eficiente, abierto y equitativo y, obviamente, más multilateral (ADDA, 1996). En efecto, la crisis de la actual ronda de negociaciones de Doha, daría evidencia como para inferir que el desvío de comercio, el proteccionismo vigente en ciertos sectores y la consolidación de áreas de comercio discriminatorias estarían amenazando la continuidad del sistema multilateral. De mantenerse en el tiempo esta situación, se restaría legitimidad, incluso, a los mecanismos institucionales establecidos por la Organización Mundial de Comercio.

Por otra parte, si la regionalización es un corolario de la globalización de la economía mundial (BERNAL-MEZA, 1994, 2000; BERNAL-MEZA, MASERA, 2005), desde una perspectiva centrada en los problemas de América Latina, la formación de espacios de integración y cooperación podría representar una estrategia coadyuvante de las políticas del desarrollo.

Consideramos que la integración regional puede ser analizada bajo el enfoque de las ganancias derivadas de la formación de un espacio regional: a) la potencial cooperación en los diversos planos y dimensiones del sistema social (política científico-tecnológica, política cultural, política industrial, etc.) entre los países miembros de un acuerdo; b) la línea estratégica fundamental para la inserción competitiva de los países en la economía internacional; c) la transformación de las sociedades en pos de un modelo de crecimiento y desarrollo; d) la coordinación de posiciones de economía política en los foros internacionales, junto a los otros miembros de un acuerdo; e) la creación de un espacio defensivo, tanto en el plano económico como en la dimensión política y cultural (por ejemplo en lo que respecta a la identidad), frente al avance de actores más poderosos, como sucede por ejemplo en el caso de las industrias culturales.

Por lo expuesto, concluimos que el vínculo entre globalización y regionalización nos permite comprender la estructura del sistema internacional desde una perspectiva temporal de la expansión del capitalismo global. Además, que en las transformaciones más recientes está jugando un rol decisivo el pujante proceso de integración económica regional entre países. 


\section{Factores de la regionalización en América Latina}

En América Latina, la cooperación y la integración han tenido, históricamente, características distintivas de aquellas que, por ejemplo, se han dado en Europa occidental o entre Estados Unidos y Canadá, puesto que las metas que se perseguían con esos instrumentos se relacionan directamente con el desarrollo económico. En efecto, la exigencia de la integración se supeditaba a ciertas insuficiencias estructurales identificadas en la región por Prebisch, en su informe de 1949. De allí en más, los análisis de la Comisión Económica para América Latina, de la cual Prebisch fue su primer secretario, detectaron diversos factores críticos que estaban presentes en los sistemas socio-económicos de los países latinoamericanos: insuficiencia en la estructura productiva, escasa oferta exportable, inadecuado avance en la construcción institucional (por ejemplo de los mecanismos financieros de pago), atraso y estancamiento de la economía rural junto a zonas de baja productividad y excesivo latifundismo, ausencia de una base tecnológica endógena en sectores dinámicos, falta de movilidad social, extrema desigualdad en la distribución del ingreso, pobreza, exclusión y fuerte fragmentación social, etc. El concepto que resumía esta situación era la heterogeneidad estructural, la que junto a una enorme dependencia del sector externo y un débil desarrollo industrial, imposibilitaba recuperar el deterioro de los términos de intercambio que producía el sistema importador-exportador. Los países de la región se habían incorporado tardíamente a una economía mundial dominada por los sectores industriales más innovadores de los países centrales.

El enfoque elaborado por la corriente cepalina asumió una visión de conjunto de la estructura de la economía mundial, sustentado en la identificación de dos áreas intervinculadas asimétricamente: el centro y la periferia. A partir de esta morfología, Prebisch formuló su teoría del "Intercambio Desigual", que pasaría a ser un fundamento específico de las políticas orientadas a impulsar procesos de integración, mediante la sustitución de importaciones y el crecimiento industrial de la región en un proceso combinado con el aumento de exportaciones y de participación en el comercio internacional (PREBISCH, 1963; CEPAL, 1959, 1969, 1974, 1982, 1987; AYZA, FICHET, GONZÁLEZ, 1975). La idea central es que a través de la implementación de políticas de cooperación regional se podrían modificar 
situaciones estructurales de subdesarrollo. Uno de los principales logros de un espacio integrado podría ubicarse en las economías de aglomeración, aunque se reconocía que debía exigirse una amplia coordinación -en los niveles nacional y regional- de las políticas de inversiones, fiscales, de salarios y precios, para evitar la tendencia a la concentración geográfica, y por ende desigual, de los beneficios y de los esfuerzos de acumulación (FURTADO, 1972, 1983).

Si tenemos en cuenta el marco de interpretación más general que nos ofrece la disciplina de las relaciones internacionales, podemos señalar que el regionalismo en América Latina ha oscilado históricamente entre dos polos: por un lado, mediante el desarrollo de esquemas de integración intra-latinoamericanos sin presencia de los Estados Unidos de América, y por otro, con el establecimiento de ámbitos de cooperación bajo la égida norteamericana (desde el Panamericanismo del siglo XIX al proyecto ALCA de fines del siglo XX). El Área de Libre Comercio de las Américas, desde su lanzamiento en 1994, representaba una nueva versión del modelo de dominación hegemónica de los Estados Unidos en el hemisferio, no sólo porque incluía en su agenda cuestiones que iban más allá de las comerciales -como inversiones, servicios, acceso a mercados, etc.- sino porque su efectiva constitución podría haber tenido profundas consecuencias para los países latinoamericanos. Podría haber significado, por ejemplo, dado el nivel de las asimetrías y el desigual carácter de los intereses en juego, el fin de los esquemas subregionales (MERCOSUR, CAN). El ALCA personificaba para los Estados Unidos un instrumento de su estrategia global y de seguridad nacional, porque se hubiera constituido en la potencia del bloque más importante del mundo en cuanto a cifras económicas, demográficas, etc. Además, el ALCA le hubiera posibilitado, entre otros factores, mejorar su posicionamiento negociador en la OMC y frenar la presencia de la Unión Europea y de las potencias asiáticas en la región (BERNAL-MEZA, MASERA, 2006).

Específicamente, el surgimiento del regionalismo latinoamericano puede ser analizado bajo tres enfoques (HURRELL, 1994): 1). Competencia política y mercantilista por el poder: según este enfoque el regionalismo es una respuesta a las presiones sistémicas ejercidas por una determinada configuración de 
las fuerzas internacionales y a la competencia ejercida por aquellos grupos de países rivales, con o sin presencia de una potencia hegemónica, que intentan acumular poder. Este enfoque, que nosotros denominamos de "regionalización estratégica", puede ser evaluado, por ejemplo, en términos de participación en mercados; 2) Factores de interdependencia: de acuerdo a este enfoque, el regionalismo surge como respuesta funcional a los problemas creados por los lazos de interdependencia asimétrica y vertical (por contener países del hemisferio norte y sur), como por ejemplo sucede en el NAFTA o Tratado de Libre Comercio de América del Norte (TLCAN), en la relación entre Estados Unidos de América y México; 3) Factores internos: según esta perspectiva, el movimiento hacia el regionalismo pone de relevancia aquellos elementos comunes de los países que participan de un esquema de integración y cooperación regional; por ejemplo, la homogeneidad étnica y lingüística, factores éstos que refuerzan el sentido de identidad de una región y que le permiten actuar como un actor unitario en la obtención de ciertas metas, y como una plataforma de promoción de los intereses comunes.

En última instancia, la trayectoria histórica de la integración regional en América Latina -de ALALC al MERCOSUR- nos muestra la dificultad inherente que supone generar espacios económicos ampliados en el marco de la estructura de poder subyacente a la economía mundial. El regionalismo nos ha revelado, en otro nivel, la especificidad de las estructuras socio-económicas de la periferia, y las limitaciones políticas y económicas que se derivan de la integración en condiciones de subdesarrollo. La reproducción de las estructuras centro-periferias al interior de los bloques junto a una marcada asimetría producto del desarrollo desigual entre las regiones son una muestra de ellas. Es para tener en cuenta la afirmación acerca de que "las periferias dinámicas continuarán siendo periferias, es decir, sociedades atravesadas por todas las principales contradicciones producidas por la yuxtaposición de enclaves modernizados, rodeados de un océano poco modernizado" (AMIN, 2003, p. 38-39). 


\section{Cooperación, concertación política y desarrollo en las relaciones externas regionales de los países latinoamericanos}

Deotra parte, enAméricaLatina existeun vínculo directo entrecooperación, concertación política y desarrollo en las relaciones externas regionales. En particular, y porque "el desarrollo económico es probablemente la dimensión esencial de las relaciones internacionales de los países subdesarrollados" (TOMASSINI, 1992), ambas, integración y cooperación son estrategias coincidentes; aunque pensamos que debe darse a la cooperación un sentido político que antecede a la cooperación económica y a la integración. Éste es el punto de vista que dio inicio al proceso del MERCOSUR, el subsistema de cooperación e integración que más expectivas ha creado entre los países del Cono sur latinoamericano desde los años de la ALALC.

Diversas experiencias, tanto de concertación y de integración regionales (así como de vinculaciones interregionales) se inscriben en lo que se ha denominado como la tercera etapa de las relaciones internacionales de América Latina. Ésta se basa en el surgimiento de nuevas formas de diplomacia multilateral o de concertación directa entre los gobiernos latinoamericanos para el manejo colectivo de los problemas internacionales; experiencias que, al menos al inicio de los años noventa, presentaban un sesgo marcadamente informal y evolutivo (TOMASSINI, 1990, 17).

Las nuevas formas de concertación directa entre gobiernos latinoamericanos, o de diplomacia multilateral a alto nivel, tienden más bien a facilitar el manejo colectivo de ciertos problemas internacionales de importancia crítica para la región, o para determinados grupos de países en un momento dado y tienen a la cooperación política como elemento esencial de sustento.

Tomando como ejemplo el estudio específico acerca del nuevo regionalismo latinoamericano, el análisis de esta etapa ayuda a evaluar en qué medida esos procesos han contribuido al surgimiento de un subsistema en que las relaciones de cooperación predominan sobre las de conflicto. Tomassini (1990) señalaba que en el futuro se podrían aprovechar cada vez más las ventajas que ofrece la complementación económica, política y cultural entre esos países, y se diera impulso a la proyección de sus intereses externos 
en un mundo fraguado en diversos circuitos productivos, tecnológicos y financieros; dividido en sólidos bloques comerciales. Por ejemplo, aún cuando los orígenes del MERCOSUR se remontan al Programa de Integración y Cooperación Argentino-Brasileño de 1986, es válida la interpretación que sostiene que tanto la profundización de los procesos de regionalización y de globalización como la emergencia de una nueva agenda política estimulada por la posguerra fría repercutieron en los comportamientos externos de los países latinoamericanos (HIRST, 1993). El efecto fue una reducción de los espacios de inserción internacionales, al tiempo que se profundizó la relativa importancia del regionalismo (Unión Europea, NAFTA).

Tal cual surge de la experiencia de los ańos noventa, la movilización política y económica hacia la regionalización en América Latina ha sido considerada, en general, como la confluencia de dos desarrollos históricos en particular: por un lado, la macroestabilización económica, lo cual convirtió a la coordinación económica en una condición necesaria para lograr cualquier grado de crecimiento económico y, por el otro, la formación de foros institucionalizados para la cooperación y negociación internacional, como resultado de Contadora y el Grupo de Río (BERNAL-MEZA, 2001).

El "dilema de los intereses comunes" es relevante para abordar la discusión sobre los procesos de integración. Es posible entender entonces el resurgimiento de la concertación latinoamericana y el lanzamiento de la regionalización desde mediados de los años ochenta como un proyecto común, como resultado de los abrumadores retos compartidos por los países: deuda externa, reestructuración macroeconómica, inestabilidad política y el desarrollo (PERALES, 1998). En este contexto, la formación de regímenes de integración, como parte de un proyecto estratégico de una región (ya sea un nuevo industrialismo o un regionalismo abierto), puede entenderse como una respuesta a las exigencias del desarrollo, en una economía mucho más internacionalizada. Pero, por estos mismos retos y desafíos, alcanzar un grado importante de institucionalidad en los esquemas de integración, es tan importante como indicador y calificador de la efectividad de los esfuerzos de regionalización (BERNAL-MEZA, 2001). 


\section{Significado de los nuevos regionalismos}

La trayectoria del regionalismo en el siglo XX ha pasado por tres fases principales. La primera es la que corresponde a los ańos 50s. y 60s., de gran énfasis en la cooperación regional con las experiencias de la Comunidad Europea (Tratado de Roma, 1957) y con la Asociación Latinoamericana de Libre Comercio -ALALC- en América Latina (Tratado de Montevideo, 1960). Podemos constatar la existencia de una segunda fase en los años 70s., cuyas características son la caída del dinamismo regionalista a causa de la desconfianza en los logros potenciales de los esquemas de integración y cooperación. En el ámbito latinoamericano, en particular, es la época de crisis de los modelos de sustitución de importaciones en lo económico y de los cambios de régimen en los sistemas políticos. En una tercera etapa, desde mediados de los años 80 s., es visible un nuevo impulso en el movimiento hacia la construcción de esquemas regionales, bajo el paradigma del regionalismo abierto y las políticas neoliberales que los sustentan, lo que generó, desde entonces, impactos significativos en la conformación de la economía mundial. El auge del regionalismo se ha dado desde entonces con tanta intensidad, que algunos autores consideran que estamos en presencia de una "transformación espacial de las relaciones internacionales” (SMOUTS, 1998), lo que significa que la economía mundial se está orientando hacia la dirección la conformación de regiones internacionales y bloques económicos.

Diversos factores han colaborado al resurgimiento de los procesos de regionalización, entre otros; 1) la firma del European Single Market Act en 1986 y el posterior Tratado de Maastricht en 1992, con el que se da nacimiento a las etapas más complejas y recientes de la Unión Europea; la caída de la Unión Soviética y la transición a la economía de mercados de los antiguos países socialistas, proceso que contribuyó al auge regionalista mediante la celebración de acuerdos de incorporación a la Unión Europea; 2) la demora en las negociaciones de la ronda Uruguay del GATT, que contribuyó a privilegiar la vía regional, aunque años después, el surgimiento de la Organización Mundial de Comercio (1994) indudablemente favoreció la difusión de regiones comerciales. Es interesante constatar que en la actualidad, una última señal para la proliferación de los acuerdos regionales nos lo da la paralización de la ronda de Doha. Como en períodos anteriores, 
la crisis sin miras de solución a corto plazo en la negociación multilateral puede derivar en un impulso de la estrategia regional. Esto es así siempre y cuando la dirigencia de los países interpreten que solamente en los ámbitos regionales se pueden llegar a alcanzar ciertas metas, muy difíciles de lograr en el sistema internacional de comercio dada la complejidad de los temas en disputa; 3) la respuesta regional a la Europa integrada, impulsada por los Estados Unidos de América (FISHLOW, HAGGARD, 1992), con la firma de la zona de libre comercio con Canadá, y años después, con la puesta en funcionamiento del Tratado con México y Canadá (enero de 1994) junto a la propuesta lanzada en la Cumbre de Miami, en el mismo año, de crear un Área de Libre Comercio de las Américas (ALCA); 4) Por su parte, en América Latina, la restauración democrática dio impulso a los programas de cooperación e integración. Es el caso del ámbito subregional, con los acuerdos PICAB entre Argentina y Brasil, a los que siguió la constitución del Mercado Común del Sur (MERCOSUR) en 1991.

Es esta proliferación de acuerdos lo que ha transformado al regionalismo en un fenómeno universal. Podemos observar, también, los espacios de comercio integrado son ámbitos más vulnerables -dado su excesivo marco regulatorio- y que se encuentran en contradicciones con otros regímenes donde a veces participan los mismos Estados.

Advertimos cambios de orden cuantitativo y cualitativo en los nuevos regionalismos. En lo que respecta al primero, las cifras nos indican que cuando el Acuerdo de Comercio sobre tarifas y aranceles (GATT) entró en vigor en 1948, los acuerdos de comercio eran casi inexistentes. En el marco del GATT, durante toda su actuación, en cerca de cuarenta años, fueron notificados un poco más de cien acuerdos bajo el artículo XXIV y la cláusula de habilitación. Desde que empieza a funcionar la Organización Mundial de Comercio (OMC), no sólo se multiplican el número de acuerdos, sino que la evidencia empírica muestra que un importante porcentaje (se estima alrededor del 55\% el del comercio mundial) se desarrolla ya en el interior de los bloques económicos (GILPIN, 2001). En todas las áreas económicas regionales se puede observar una mayor concentración de los volúmenes de comercio e inversiones entre los países de la tríada regional mundial (Europa Occidental, América del Norte, Asia Oriental), paralelamente a un aumento 
del comercio intrazona en el conjunto de los intercambios mundiales. Acompańando este movimiento hacia el regionalismo, se firmaron y notificaron al sistema multilateral de comercio más de cien acuerdos, exclusivamente durante la década de los noventa (BOUZAS, 2001).

Es de notar que existe también un cambio cualitativo en los actuales procesos regionales (GANA, 1994), porque en las agendas de negociación de los nuevos acuerdos se incorporan temas que ya no se refieren sólo a cuestiones arancelarias o comerciales, sino que pueden ser incluidas otras materias (inversiones, migraciones, terrorismo, mercado del trabajo, narcotráfico, transferencia de tecnología, políticas de cooperación industrial, etc.), abarcando incluso cuestiones de carácter tradicionalmente consideradas como del ámbito interno, soberano de un estado nación.

Otra novedad de alto impacto en las relaciones internacionales es el hecho que, desde hace algunos años, se celebran acuerdos no sólo entre países, sino entre bloques, por ejemplo, la asociación bi-regional Unión Europea-América Latina, o los acuerdos Unión Europea-Mercosur (ambos aún en etapas de negociación). Un lente más fino nos revela que el regionalismo ya no es cerrado como en el pasado, sino que tiende a ser abierto, de carácter vertical y asimétrico, puesto que se puede dar entre países desarrollados y en vías de desarrollo, del norte y del hemisferio sur. Además, los actuales esquemas de integración y cooperación regionales son acuerdos complejos, porque se desarrollan bajo una multiplicación de actores e intereses sectoriales. Por último, las agendas son más conflictivas, por los numerosos obstáculos y condicionamientos que existen en la discusión y por los efectos no deseados en las sociedades de los países que integran los acuerdos (BOUZAS, FANELLI, 2001a).

\section{Conclusión}

El regionalismo es un elemento clave del orden económico internacional surgido después de la segunda guerra mundial. Los países que comparten un espacio regional, se unen para lograr una mejor capacidad de negociación internacional, de competitividad en los mercados mundiales y, potencialmente, para lograr objetivos mediante la coordinación de esfuerzos en los foros internacionales, en la labor de atracción de inversiones o en el 
desarrollo de proyectos industriales y tecnológicos conjuntos.

Una de las conclusiones del presente estudio nos indica que la regionalización de la economía mundial se nos muestra como un proceso ciertamente pujante, caracterizado por la formación de espacios de integración y cooperación junto al desarrollo de la conciencia regionalista. Otra se refiere al hecho que hay un directa vinculación entre la transformación del escenario de las relaciones internacionales en los últimos decenios y la tendencia a la diversificación de los espacios regionales. Ahora bien, si la regionalización es contraria, simultánea o derivada del proceso de globalización/mundialización, es un tema cuyos argumentos se encuentran todavía en discusión. De lo que no pueden quedar dudas es que el regionalismo es una estrategia plenamente aceptada por los países en la formulación de sus relaciones económicas externas, y que esta vía coexiste -a veces conflictivamente- con la multilateral. En este sentido, todavía estaría por ser evaluada de un modo más concluyente y menos ideológico, la articulación del regionalismo con el sistema internacional de comercio.

Si la regionalización supone que los países miembros de un acuerdo buscan la obtención de ventajas comerciales y estratégicas mediante el establecimiento de un espacio integrado, el escenario multilateral nos muestra que los potenciales beneficios a obtenerse con la liberalización comercial en diversas áreas, pueden quedar diluidos si no hay reciprocidad en la concesión de preferencias comerciales y en los accesos a los mercados. Esta situación puede tornarse más conflictiva porque los temas de la agenda de los nuevos regionalismos - al igual que en la OMC- no son exclusivamente comerciales. En efecto, los temas que se están incorporando de modo progresivo en las negociaciones desbordan los tópicos tradicionales (por ejemplo, aranceles) e incluyen, según hemos considerado, cuestiones nuevas e, incluso, algunas novedosas (brand issues y new brand issues), tales como las regulaciones del mercado del trabajo, los estándares ambientales, la migración de personas o los movimientos de capital. Estas realidades que reflejan los movimientos regionales en relación con el orden económico mundial, generan fuertes condicionamientos sobre los lineamientos externos de los países y sobre la formulación de sus políticas internas. En otro trabajo, habría que analizar los nuevos rumbos de la cooperación y su reflejo en el campo de las negociaciones multilaterales. 
En lo que a nuestro ámbito regional se refiere, los cambios estructurales en la economía global y la configuración de un orden económico fundado en gran parte en la dinámica del regionalismo, ha promovido en América Latina el resurgimiento, aggiornarmiento o renovación de los esquemas ya existentes, e incentivando la conformación de nuevos espacios de integración como son los actuales esfuerzos, impulsados por algunos países, de transformar el MERCOSUR y la Comunidad Andina de Naciones (CAN) en un ámbito de cooperación más amplio, tal la Unión de Naciones Sudamericanas (UNS), también llamada Comunidad Sudamericana de Naciones. Observamos que en este proyecto, liderado por Brasil como potencia regional indiscutible del Cono Sur, resta profundizar la discusión sobre el mejoramiento de la infraestructura regional en el marco de la Iniciativa IIRSA (BERNALMEZA, SAHA, 2005). Asimismo, la UNS podría ser el comienzo de una solución para los problemas derivados de la superposición excesiva de procesos paralelos de cooperación e integración y de frentes simultáneos de negociación.

La crítica que realizamos desde nuestra perspectiva latinoamericana, es que los objetivos del regionalismo aparecen hoy más vinculados a la inserción en los mercados internacionales, y a una articulación externa de los países de la región con los centros dinámicos de la economía mundial, que al logro de una transformación real de las estructuras socio-económicas aún poco competitivas, heterogéneas y fragmentadas; porque, en definitiva, la inserción, por más exitosa que sea, no puede suplir la ausencia de una verdadera estrategia de desarrollo. 


\section{Referencias Bibliograficas}

ADDA, Jacques. La mondialisation de l'économie. Paris: Editions La Découverte, T. II "Problémes", 1996.

AMIN, Samir. Más allá del capitalismo senil. Buenos Aires: Piados, 2003.

ATKINS, George Pope. América Latina en el sistema político internacional. Buenos Aires: Grupo Editor Latinoamericano, 1991.

AYZA, Juan; FICHET, Gerardo; GONZALEZ, Norberto. América Latina: integración económica y sustitución de importaciones. México D.F.: Fondo de Cultura Económica- Naciones Unidas, 1975.

BAALAM, David; VESETH, Michael. Introduction to international political economy. New Jersey: Prentice Hall-University of Puget Sound, 2004.

BALASSA, Bela. Teoría de la integración económica. México: UTEHA, 1980.

BAYNE, Nicholas; WOOLCOOK, Stephen. The new economic diplomacy. England, Aldershot: Ashgate Publishing Limited, 2003.

BERNAL-MEZA, Raúl. Claves del nuevo orden mundial. Buenos Aires: GEL, 1991.

. América Latina en la economía politica mundial. Buenos Aires: GEL, 1994.

- Globalización, regionalización y orden mundial: los nuevos marcos de inserción de los países en desarrollo. En: RAPOPORT, Mario (Ed.). Globalización, integración e identidad nacional. Análisis comparado ArgentinaCanadá. Buenos Aires: Grupo Editor Latinoamericano, 1994a, p. 45-65.

. Sistema Mundial y MERCOSUR. Buenos Aires: GEL, 2000.

. Institucionalización del MERCOSUR. En: Dieter BENECKE, W.; LOSCHKY, Alexander (Eds.). Mercosur. Desafío político. Buenos Aires: CIEDLA/Konrad Adenauer Stiftung, 2001, p. 19-80.

BERNAL-MEZA, Raúl; MASERA, Gustavo. Desarrollo regional en el nuevo contexto global: una perspectiva neoestructuralista desde la periferia En: BERNAL-MEZA, Raúl; SAHA, Suranjit K. Economía mundial y desarrollo regional. Buenos Aires: Nuevohacer/Grupo Editor Latinoamericano, 2005. 
. Free trade for the Americas? The United States' push for the FTAA agreement. VIZENTINI, Paulo; WIESEBRON, Marianne (Dir.). Etudes Internationales, Compte Rendu: Régionalisme et Régions - Amériques, London, Zed Books, 2004, 242 p., v. 37, n. 2, juin. 2006.

- Sociedad de la información: etapa posterior de la globalización/ mundialización. Desafíos y riesgos para América Latina. Realidad Económica, Buenos Aires, n. 227, p. 90-117, abr./mayo. 2007.

BERNAL-MEZA, Raúl; SAHA, Suranjit K. Economía mundial y desarrollo regional. Buenos Aires: Nuevohacer/Grupo Editor Latinoamericano, 2005.

BOUZAS, Roberto. Multilateralismo y regionalismo. Consejo Profesional de Ciencias.Económicas de la Ciudad Autónoma de Buenos Aires. Los desafíos del nuevo escenario económico internacional. Buenos Aires: Editorial La Ley, exposición en el V Congreso de Economía, p. 47-54, 2001.

BOUZAS, Roberto; FANELLI, José María. MERCOSUR: integración y crecimiento. Buenos Aires: Fundación OSDE-Universidad Gral. San Martín, 2001a.

CAPORASO, James. Enfoques teóricos sobre la cooperación internacional: el caso de América Latina. En: MUÑOZ, Heraldo; VICUÑA, Francisco Orrego (Comps.). La cooperación regional en América Latina. Diagnóstico y Proyecciones Futuras. México D.F.: El Colegio de México-Universidad de Chile, 1987.

COMISION ECONOMICA PARAAMERICA LATINA (CEPAL). ElMercado Común Latinoamericano. Santiago: Naciones Unidas, E/CN.12/531, 1959. . El Pensamiento de la CEPAL. Santiago/Chile: Editorial Universitaria, 1969.

- Algunas conclusiones relativas a la integración, la industrialización y el desarrollo económico de América Latina. Boletín Económico de América Latina, Naciones Unidas, v. XIX, n. 1 y 2, 1974.

. Integración y cooperación regionales en los años ochenta. Serie Estudios e Informes de la CEPAL, Santiago, Chile, Naciones Unidas, n. 8, 1982.

_. Relaciones económicas internacionales y cooperación regional de América Latina y el Caribe. Serie Estudios e Informes, Santiago, Naciones Unidas, n. 63, feb. 1987. 
. Globalización y desarrollo. Santiago: Chile, Naciones Unidas, 2002.

COSTA VAZ, Alcides. Cooperação, integração e processo negociador. Brasília D.F., FUNAG-IBRI, 2002.

COX, Robert. Social forces, states and world orders: beyond international relations theory. Postcript. En: KEOHANE, Robert O. (Ed.). Neorealism and its critics. New York: Columbia University Press, 1986, p. 218-249.

FAWCET, Louise; HURRELL, Andrew (Comps.). The new regionalism and international order. Oxford: University Press, 1993.

FISHLOW, Albert; HAGGARD, Stephan. The United States and the regionalization of the world economy. Paris: OECD, Development Centre Documents, 1992.

FURTADO, Celso. Teoría y política del desarrollo económico. 4. ed. México D.F.: FCE, 1972.

Breve Introducción al desarrollo. México D.F.: FCE, 1983.

GANA, Eduardo, (Edit.). La dinámica y los nuevos estilos de la integración económica en América Latina y en Europa. Pensamiento Iberoamericano. Revista de Economía Política, n. 26, jul./dic., p. 17-42, 1994.

GILPIN, Robert. Global political economy. Understanding the International Economic Order. Princeton/New Jersey: Princeton University Press, 2001.

HIRST, Mónica. Las relaciones internacionales de América Latina a mediados de los 90s.: nuevos desafíos y viejos dilemas. América Internacional, Buenos Aires, FLACSO, v. 1, n. 2, 1993.

HURRELL, Andrew. Regionalismo en las Américas. En: LOWENTHAL, Abraham; TREVERTON, Gregory (Comps.). América Latina en un Mundo Nuevo, México D.F., Fondo de Cultura Económica, p. 199-226, 1994.

KRIPPENDORFF, Ekkehart. El sistema internacional como historia. México D.F.: Fondo de Cultura Económica, 1985.

KRUGMAN, Paul; OBSTFELD, Maurice. Economía internacional. Teoría y política. Madrid: McGraw-Hill/Interamericana de Espańa S.A., 1999. 
PERALES, José Raúl. La cooperación regional institucionalizada y los retos de la crisis estructural en América Latina. Estudios Internacionales, Santiago, Chile, Año XXI, n. 121-122, p. 88-111, 1998.

PREBISCH, Raúl. Hacia una dinámica del desarrollo latinoamericano. México, D. F.: Fondo de Cultura Económica, 1963.

SMOUTS, Marie-Claude. La région comme nouvelle communauté imaginaire? In: LE GALES, Patrick ; LEQUESNE, Christian (Dir.). Les paradoxes des régions en Europe, Paris, La Découverte, 1997.

. (Dir.). Les nouvelles relations internationals. Pratiques et théories. Paris: Presses de la Fondation Nationale des Sciences Politiques, 1998.

SUNKEL, Osvaldo. Las relaciones centro-periferia y la transnacionalización. Pensamiento Iberoamericano. Revista de Economía Política, Madrid, n. 11, enero-junio. 1987.

TAMAMES, Ramón; HUERTA, Begoña. Estructura económica internacional. Madrid: Alianza, 1999.

TOMASSINI, Luciano (Comp.). Transnacionalización y desarrollo nacional en América Latina. Buenos Aires: GEL, 1984.

. (Comp.). Nuevas formas de concertación regional en América Latina. Buenos Aires: RIAL/Grupo Editor Latinoamericano, 1990.

- Desarrollo económico e inserción externa en América Latina: un proyecto elusivo. Estudios Internacionales, Santiago, Chile, Año XXV, n. 97, p. 73-116, enero-marzo 1992.

TUGORES, Juan. Economia internacional. Globalización e integración regional. Madrid: Mc Graw Hill, 2004.

WALLERSTEIN, Immanuel. Le capitalisme historique. Paris: Éditions La Découverte, 1985. 